\title{
Exploring contemporary illustrations of Scottish identity through a study of Scottish fashion influencers on Instagram.
}

MARCELLA-HOOD, M.

2019

(c) Edinburgh University Press. This is an Accepted Manuscript of an article published by Edinburgh University Press in Scottish Affairs. The Version of Record is available online at:

https://www.euppublishi...0.3366/scot.2019.0294. 


\title{
Madeleine Marcella-Hood
}

\section{Exploring contemporary illustrations of Scottish identity through a study of Scottish fashion influencers on Instagram}

\begin{abstract}
This paper explores the construction of Scottish identity and place amongst fashion and style influencers on Instagram. Existing research and information surrounding the Scottish fashion industry is sparse and focused on traditional textiles, such as tartan and tweed. Style influencers have revolutionised the fashion industry and it is argued that, by identifying as Scottish or Scotland-based on Instagram, these individuals are shaping perceptions of Scottish identity and place, acting as contemporary cultural icons.
\end{abstract}

The study consists of 14 interviews, where participants were also asked to provide a selection of posts that they felt demonstrated their identity as a Scottish fashion influencer. Participants expressed pride in their Scottish identity and surroundings; this was revealed through their desire to promote Scottish designers and destinations. They did not see tartan as a feature of their own style but recognised its value in Scotland's fashion story. People and place-related symbols were regarded as more authentic representations of Scottish identity and style. This research contributes to the field of Scottish studies by presenting contemporary illustrations of Scottish fashion through the influencers who are shaping these.

\section{Keywords}

Scottish, Scotland, fashion, identity, style, national, Instagram

Dr Madeleine Marcella-Hood is a lecturer within the School of Creative and Cultural Business at Robert Gordon University where she teaches subjects in the area of fashion communication and business. She is particularly interested in the area of Scottish fashion and identity. Madeleine's previous research concentrates on the adoption of project management within the fashion industry in Scotland. 


\section{Exploring contemporary illustrations of Scottish identity through a study of Scottish fashion influencers on Instagram}

Anderson (1983) emphasises the importance of contemporary representations and reproductions of nationhood, arguing that these are what sustains a nation. It has since been suggested that these illustrations are particularly important for stateless nations like Scotland (McCrone et al, 1995; Martin, 2009). There has been much animated discussion around Scottish identity and what it means to be Scottish, particularly in terms of how this is expressed and understood (McCrone et al, 1995; Kiely et al, 2001; Bond and Rosie, 2002; Bond and Rosie, 2006; Bechhofer and McCrone, 2009; McCrone 2017). Scotland's dynamic political landscape has reinvigorated these discussions, e.g. the Scottish Independence Referendum (2014) and Brexit (2016), where the latter saw every Scottish council area vote to remain in the European Union and an overall UK outcome to leave.

In their exploration of Scotland the Brand, McCrone et al (1995) investigate the construction of Scottish heritage. They explain that 1822 was a landmark in Scotland's story, when Sir Walter Scott arranged King George IV's Scottish visit (the first since the Battle of Culloden in 1746), styling him in full Highland regalia for an organised meeting with Clan Chiefs. McCrone et al denote this event as the beginning of tartanry, where tartan (which had previously only ever been associated with the Highlands) became symbolic of a romantic and mythical vision of Scotland at large.

Scotland as a 'country' is a landscape of the mind, a place essentially of the imagination (McCrone, 2017: 406).

The Highland myth surrounding Scotland was further popularised when Queen Victoria acquired the Balmoral estate in 1852 and famously used this as a retreat to escape London life, taking refuge in the landscape and relishing the fresh Scottish air. With these events in mind, it could reasonably be argued that Sir Walter Scott was one of the earliest Scottish fashion influencers; he is credited (or sometimes criticised) with having invented tartanry through his novels and orchestration of the Royal Visit (Brown, 2010). 
McCrone et al (1995) propose that Scotland might be a victim of its own rich heritage where there is too great a focus on the past, making it difficult to establish a modern identity. Equally, it is argued that national identities must be reviewed and reimagined periodically in order for a culture to thrive (McCrone et al, 1995; Crawford, 2007; Kjartansdóttir, 2011).

This argument is particularly pertinent at times of political change and where there have been dramatic shifts in society, such as the advent of social media and debates on the nation. This paper explores the construction of Scottish identity and place through interviews with Scottish fashion and style influencers around their use of Instagram. The research sought to uncover how their online identity and personal style are informed by a sense of national identity and place and how they convey this in words and images.

\section{Scottish fashion}

Fashion lends itself to being an optimal synthetic indicator of a nation's position, amidst memory, mystification, and imaginary (Segre Reinach, 2015: 271).

The Scottish fashion industry is supported today by a growing number of fashion and design graduates; it accounts for over 8,000 jobs and contributes significantly to the Scottish economy and its culture (Lennon, 2016). However, there is a significant lack of research and information on Scottish fashion and, where this does exist, it is predominantly driven by universities and public sector organisations.

Only a small number of studies consider fashion and Scotland together: the majority of these tend to take a retrospective approach and focus on the production of Scottish textiles (Grierson et al, 1985; Butt, 1987; Porac et al, 1989; Fulton, 1991; Cheape and Anita, 2005; Faiers, 2008; McKeen, 2009; Brown, 2010; Platman, 2011; Rae, 2016; Young and Martin, 2017). The Scottish textile industry is both profitable and globally recognised: Scotland has a strong reputation for producing high quality, artisan 
garments, including Harris Tweed and Scottish tartan (Fulton, 1991; Platman, 2011; Young and Martin, 2017; Scotland, 2017).

The worst excesses of tartanry verge on the ludicrous, and yet in other manifestations, it is high fashion (McCrone et al, 1995: 56).

Scottish national dress is referenced widely in the fashion industry. In 2012, Chanel hosted a fashion show for its pre-fall 2013 collection in the ruins of Linlithgow Palace in Scotland, Mary Queen of Scots' birthplace (Figure 1). This showcased Karl Lagerfeld's interpretation of Scottish dress, with tartan and tweed as the prevailing ideas (Alexander, 2012). The coverage of the event in Vogue claimed 'there was something quintessentially Scottish in the air. 'Barbarian romance', Lagerfeld called it' (Blanks, 2012: np).
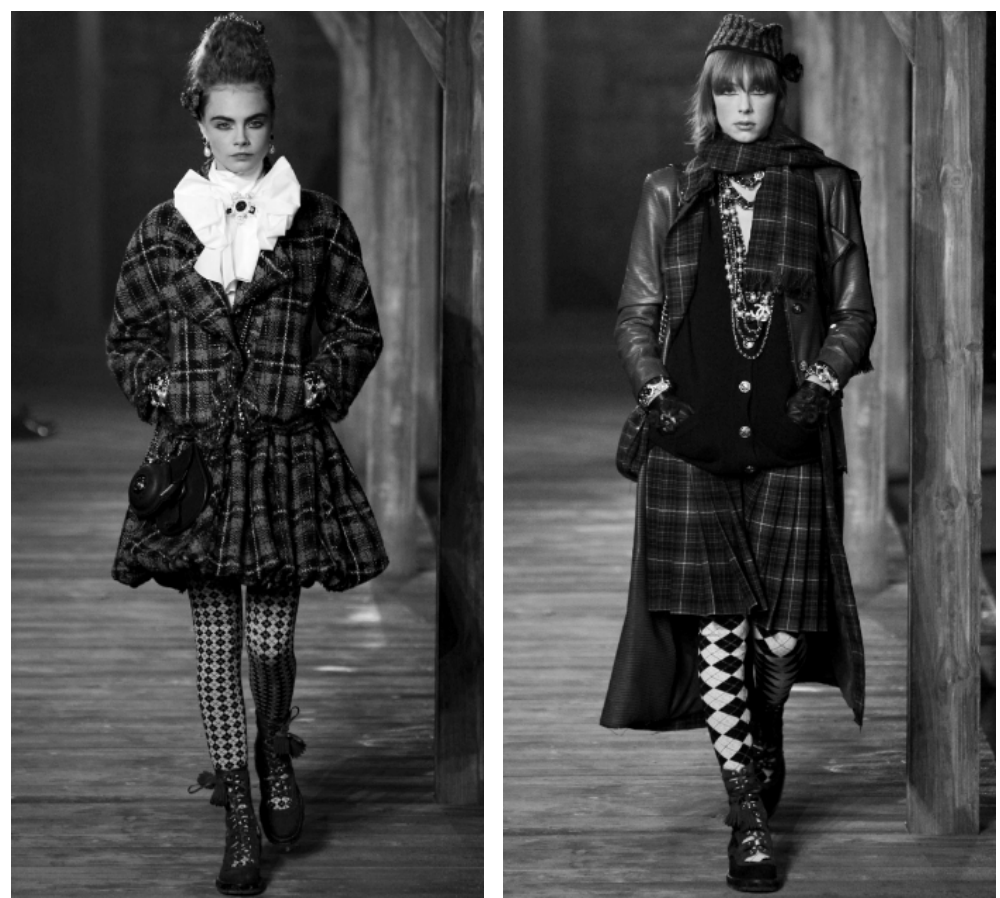

Figure 1: Looks from the Chanel pre-fall 2013 collection (Blanks, 2012: np)

Chanel has used Scottish wool in its designs since the brand's inception in 1910, when Coco Chanel was famously inspired by the Scottish Highlands as well as designs and textiles from the region. Her love of tartan and tweed are evident in a number of her classic garments, perhaps most notably the Chanel suit (Young and Martin, 2017). The brand's Linlithgow show followed shortly after their acquisition of the Barrie Knitwear 
cashmere mill in the Borders, saving it from closure (BBC, 2012). The mill, alongside others like Johnson's of Elgin, supply to luxury fashion brands across the globe. Today, these businesses have become recognised in their own right as luxury fashion brands, selling directly to customers as well as supplying to businesses like Chanel, Hermès and Burberry.

Vivienne Westwood is a designer who has brought Scottish national dress to the fore at various points in her career, frequently using tartan and tweed in her designs. The English designer became a figurehead for Scottish identity when she famously - and controversially - spoke out in favour of Scottish independence in the run up to the 2014 Referendum. Westwood appeared in a series of images and sent her models onto the catwalk at London Fashion Week wearing 'yes' badges (Figure 2; Edwards, 2014). Most other designers refused to become involved in the issue so publicly. However, in the days leading up to the vote, the British Fashion Council and Alexandra Schulman, of British Vogue, spoke out against Scottish independence, citing the excellence of Scottish textiles and Scotland's design graduates as instrumental in the success of British fashion (Jones, 2014).

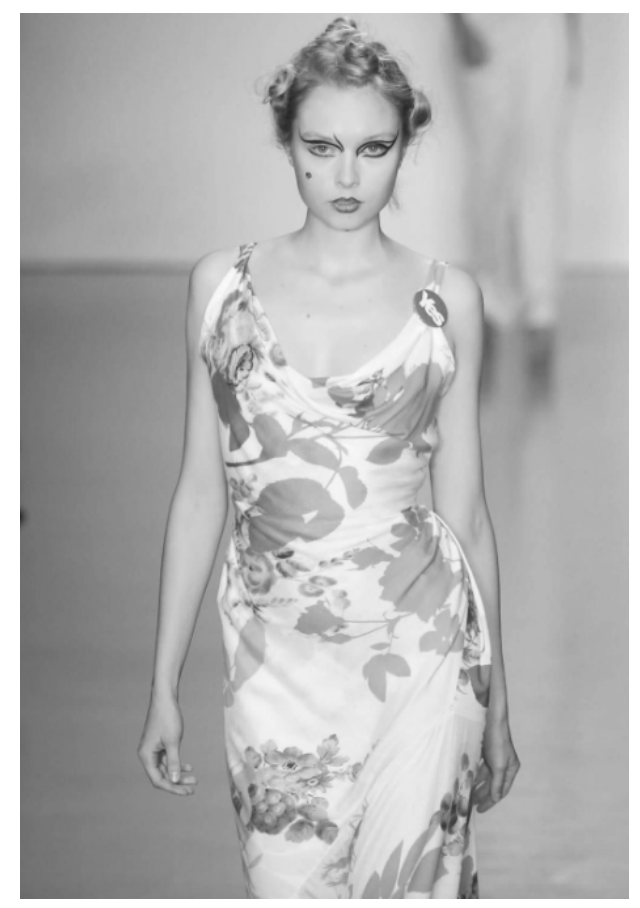

Figure 2: Vivienne Westwood spring 2015 collection (Edwards, 2014) 
Westwood is recognised, perhaps most strongly, for her political influences, where she is linked to prevalent subcultural movements, such as Punk (1970s) and Grunge (1990s) (Percival, 2010). Through these subcultural movements it is argued that tartan was 'reimagined' (Percival, 2010, p. 203) signifying 'both belonging and countercultural resistance' (ibid, p. 208). This might be described as a historical throwback to Jacobite uprisings when tartan was seen as a symbol of rebellion and subsequently banned for a period (Young and Martin, 2017). Young and Martin (2017) and Percival (2010) suggest that the 1970 s was a particularly influential period, which saw tartan adopted and appropriated in new and interesting ways. This was brought to an international stage through the Bay City Rollers who famously 'turned the whole world tartan', perhaps also cementing the style as more mainstream (Lindfield-Ott, 2018: np).

The Scottish landscape is also celebrated within the fashion industry where, for example, Pringle of Scotland (2009) showcased its heritage by teaming up with Scottish actress Tilda Swinton and Scottish film-maker Ryan McGinley. Together they created a short film, set in the ruins of Duffus Castle that showed the actress traveling through caves, forest and beach, chosen as key signifiers of Scotland (Figure 3).

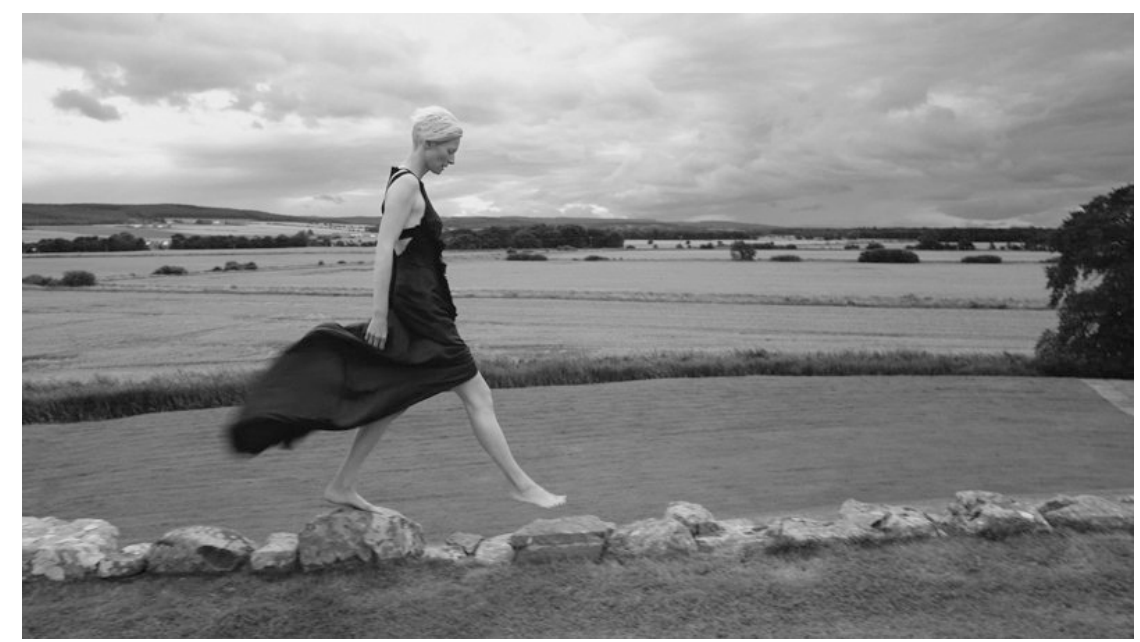

Figure 3: Pringle of Scotland film (directed by Ryan McGinley, 2009)

More recently, Sarah Burton, Creative Director of the Alexander McQueen brand, paid homage to Scottish place and heritage in the spring-summer 2017 collection using traditional Scottish crafts from Shetland (Chen, 2016). Mower (2016: np), in Vogue, 
reported the collection with a strong emphasis on place. The Scottish Highlands were described in stark contrast to the brand's headquarters in London:

They walked the dramatic landscapes, photographed wild flowers, watched birds wheeling in the skies, and surf crashing in on deserted beaches. They researched the living traditions carried out by the crofters, a tiny community which has knitted wool lace shawls for hundreds of years. Then they came back to the McQueen studio in gritty, urban London, inspired to make a show from everything they'd seen.

This description is intriguing and resonates with the Highland vision of Scotland as stark and people-less, a place where one can escape London life. The collection builds on the work of the late Alexander McQueen, who was influenced by his own Scottish heritage and cited this in his earlier collections Highland Rape (1995) and Widows of Culloden (2006).

These examples demonstrate that Scottish identity is both influential and recognisable in the increasingly globalised fashion industry. They emphasise heritage, history, craftsmanship and a strong sense of place as important in the case of Scottish fashion. However, it could be argued that they further entrench images of tartanry and the Highland myth surrounding Scotland.

There has been increasing interest in studies of fashion and national identity and further work is invited in the field (Mora and Rocamora, 2015). Whilst it has been argued that Scotland suffers from too much heritage (McCrone et al, 1995), it is also argued that nations like Denmark face the opposite problem; where national designs tend not to be attributed to Denmark because they are not reccognised as part of an existing aesthetic (Skov, 2010). This suggests that if Scotland did not have such a rich cultural heritage then it would be searching for and attempting to construct one. However, it also suggests that only Scottish designs that include traditional textiles or elements of tartanry will be recognised as Scottish. 
Perhaps, as McCrone et al (1995) argue is the case with Scottish heritage more generally, tartan and tweed are such dominant signifiers of Scottish fashion, they eclipse any further conceptualisations of Scottish fashion and style that might exist. Conversely perhaps we, as academics, are responsible in our focus on these dominant tropes for further entrenching the Scottish myth (Cederlund, 2011).

\section{Fashion and style influencers}

Rocamora (2011: 101) highlights a shift in the fashion media landscape in the early wave of fashion blogging, where the phenomenon widened the geography of the industry conveying 'a fashion that is not centred on established designers and key cities only, on the voice of the traditional expert'. In Scotland there is a lack of traditional fashion media (Marcella and Rowley, 2015). As fashion commentary has shifted online and where social media has superseded more traditional forms of fashion communication and criticism, Scotland might have found its voice, amongst the 'real people' who share their personal style on platforms such as Instagram (ibid: 102). The majority of fashion and style influencers are female and might be recognised for their contribution to a more feminine or at least less masculine image of Scottish identity; progressing 'the cultural association of Scotland with the figure of the brawny kilted Highlander' (Martin, 2009: 8).

Crawford (2007) explores Scotland's Books and maintains that, at its best, literature forms ideas and replaces old narratives around national identity. In today's increasingly digital and visual culture, fashion and style influencers might act in the same way, serving as contemporary cultural icons. The aim of this study was to explore the construction of Scottish identity and place amongst fashion influencers on Instagram. This paper reflects on the expressions and illustrations of Scottish identity and fashion that were uncovered. 


\section{Methodology}

This qualitative study consisted of interviews with 14 fashion influencers who identified as Scottish, Scotland-based or within a Scottish city in their Instagram biography. This character-limited description is used to reveal characteristics of an online identity and commonly consists of elements such as age, interest(s), genre, etc (Table 1). The small sample size was informed by other studies, including Crane et al's (2004) study of Scottish Dress, Ethnicity and Self-identity that consisted of 11 interviews and where the authors reported data saturation by the ninth interview.

Table 1: Participants' Instagram biographies (anonymised where relevant)

\begin{tabular}{|c|c|}
\hline $\begin{array}{l}\text { Participant } \\
\text { (age) }\end{array}$ & Biography description \\
\hline Arran (25) & $\begin{array}{l}\text { Fashion + lifestyle blogger, daydreamer and lover of all things shiny, } \\
\text { from bonnie old Scotland }\end{array}$ \\
\hline Barra (26) & $\begin{array}{l}\text { Lifestyle blogger and PR account manager, handy baker, Aberdeen, } \\
\text { Scotland }\end{array}$ \\
\hline Cara (21) & $\begin{array}{l}\text { Clothes, cats and cake. Lifestyle, fashion, travel, food \& beauty blogger } \\
\text { from Glasgow, Scotland }\end{array}$ \\
\hline Danna (27) & $\begin{array}{l}\text { \{name of husband }\},\{\text { name of son }\}, \text { names of cats }\}, \text { Scotland, Australia, } \\
\text { Quatar (soon) }\end{array}$ \\
\hline Eday (20) & $\begin{array}{l}\text { Edinburgh fashion blogger, fashion communication student, the Scottish } \\
\text { Design Exchange, Fashion fix daily, SHOWstudio }\end{array}$ \\
\hline Fara (30) & $\begin{array}{l}\text { Musings of a life enriched with travel. UK luxury travel blogger. Top } 10 \\
\text { Scottish blogs. Researcher at*** }\end{array}$ \\
\hline Gunna (24) & Style blog. Scottish girl in London, fashion and personal style blogger \\
\hline Hirta (24) & Lifestyle blogger, wife of ${ }^{* * *}$, vegan, Aberdeen \\
\hline Iona (23) & Blogger at $* * *$, journalist, I like nice clothes, Scottish girl in North London \\
\hline Jura (25) & Streetstyle, lifestyle, beauty \& travel, Glasgow \\
\hline Lungay (24) & \#psoriasis warrior | blogger | traveller, Glasgow, Scotland \\
\hline Mull (29) & Style and travel enthusiast, Aberdeen, Scotland \\
\hline Skye (23) & $\begin{array}{l}\text { Scottish blogger, vegetarian, cat mother, book enthusiast, all round music } \\
\text { junkie and chocolate addict }\end{array}$ \\
\hline Tiree (19) & $\begin{array}{l}\text { Scottish lifestyle blogger and fashion student, currently in Edinburgh. } \\
\text { Fitness, travel, personal development }\end{array}$ \\
\hline
\end{tabular}

Instagram users are not searchable by location or biographical description. These participants self-selected as part of a purposive sample of targeted individuals who met the criteria and were invited to participate in the study. This resulted in 29 potential interviewees, who were contacted via a private message on Instagram: 14 influencers responded, all of whom were interviewed. There was a lack of diversity amongst the 
group: all participants were women aged between 19 and 30 years; all were students or educated at a university level; and all were white.

In advance of the interview, participants were asked to provide a selection of posts they felt most strongly demonstrated their identity as a Scottish fashion influencer. This is a novel photo-interview approach that enabled the researcher to gain an objective sense of how participants viewed their own identity (Reed, 2006) and how Scottishness or their Scottish location influenced this. The inclusion of these additional texts was important in helping draw meaningful conclusions around the complex area of identity in a strongly visual setting and where a verbal narrative was not deemed sufficient to convey this (Larkin and Thompson, 2011). It also created a data set of texts for analysis that could be regarded as illustrative of contemporary Scottish identity and style. Themes were drawn from interview data and participants' texts: these data were analysed independently then across the set for commonalities (ibid).

When presenting the research findings, a consistent pseudonym is used for interview data and imagery relating to each individual participant. Participants are named after Scottish Isles and it should be noted that these locations serve no purpose beyond providing a means of differentiation and partial anonymity to participants. However, participants might be recognised due to the visual and, at times, personal nature of their Instagram posts. This means that their responses could not be completely anonymised. Participant consent was obtained for the use of self-selected imagery alongside quotations and interview data. The following discussion explores the key findings.

\section{Findings}

On the surface, for the reasons mentioned previously, the participants in this study were not a diverse group. However, they were more diverse in the variety of ways in which they imagined their Scottish identity. The majority of the participants (11) were living in three of Scotland's four largest cities, two participants were living in London and one in Perth, Australia. Amongst these, three participants had been born in England but were now living in Scotland and one was born and had spent most of her life in 
Greece before moving to Aberdeen. The fact that these influencers were all women might also be considered valuable in providing insights into contemporary Scottish identity and style, where popular representations of Scotland are acknowledged as being predominantly masculine (McCrone et al, 1995; Martin, 2009).

Participants were asked to define their national identity both openly and using the Moreno question (1988). In their responses, most chose to indicate a dual identity or presented a preference towards Scotland. There did not seem to be a correlation between those who had been born in Scotland and strength of feeling towards their Scottish identity. Those who had been born outside of Scotland tended to feel a little less comfortable in categorising themselves as Scottish using the Moreno question but were passionate about Scotland and felt a sense of belonging to the nation, which had grown over time. These individuals were, at times, communicating their Scottish identity more forcefully than those who were born and brought up in Scotland.

Eday was born and spent most of her childhood in Birmingham but had moved to Edinburgh with her family, where she now works and studies. She described Scotland and particularly Edinburgh as somewhere that had 'made an impression' on her. She reflected on feeling a sense of Scottish pride so strong that it took her by surprise. Her sample posts were constructed around her fashion identity, where her outfit posts tended to be photographed near her home (Figure 4). 


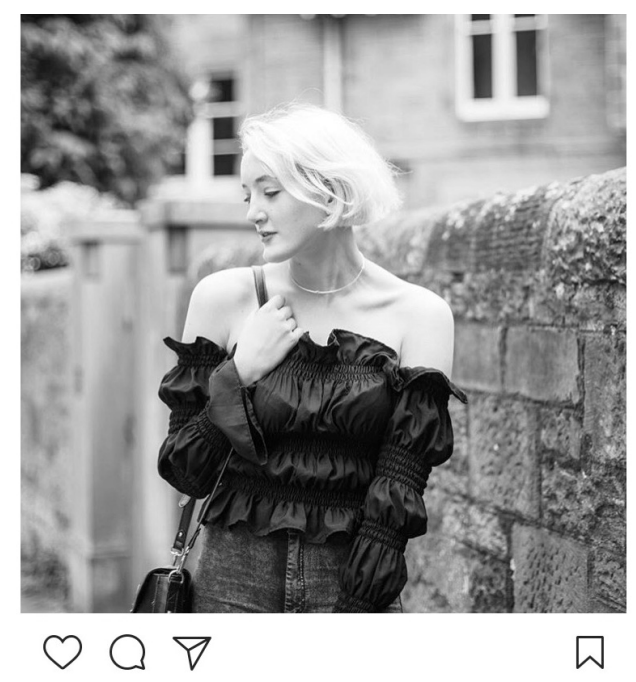

Totally in love with my new

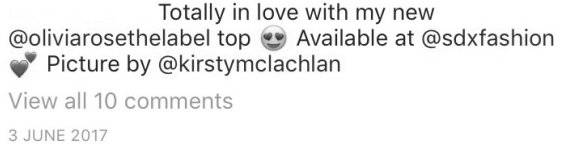

Figure 4: Eday near her home in Edinburgh

Scottish pride was connoted in a number of the sample posts and was supported in participants' discussion of these; for example, expression of a conscious desire to promote Scottish places or brands. Eday's sample images all contained garments from Scottish designers whom she saw it as the job of influencers like herself to help promote (Figure 5). 


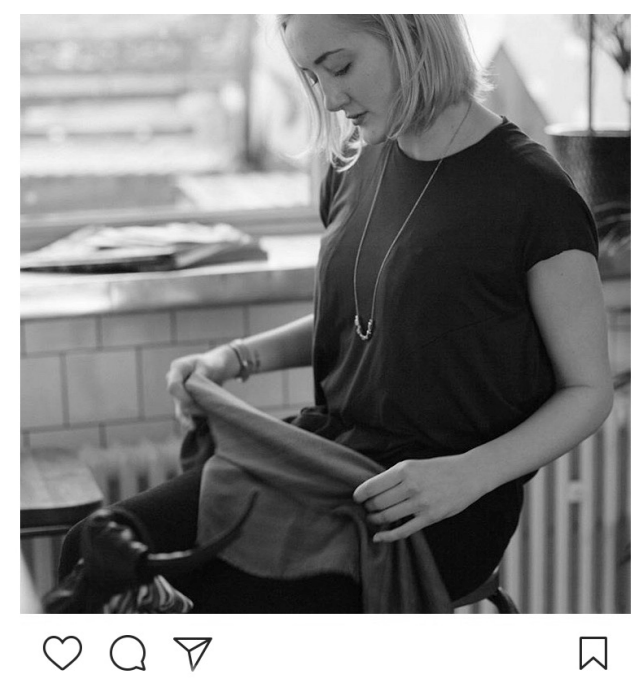

New post on the blog (link in bio): Green Is The New Black, all about why \#sustainable and \#ethical fashion is more than just a 'trend'. Picture by @holly__may ft my favourite @nublvck scarf and @hayleymcsporran_top \#shopscottish

Figure 5: Eday promoting Scottish brands

Other participants concurred that promoting Scottish brands was a way in which they constructed their Scottish identity online. Although the participants in this study had all received commercial opportunities through Instagram (i.e. payment and free products), those who mentioned Scottish brands agreed that it was important for them to support these and were more inclined to do so out of good will simply because they were Scottish.

Participants' passion for Scottish brands is one of the ways in which they were found to be celebrating Scotland and conveying a sense of national pride. Throughout the interviews participants made statements like: 'I'm proud of my Scottish heritage' (Iona, living in London); 'I'm really proud to be Scottish and English' (Cara, born in England but living in Glasgow); 'I'm really proud to say I am Scottish' (Arran, Aberdeen); 'Proud to be Scottish but I'm still very proud to be British' (Barra, Aberdeen); 'I still feel so proud to be Scottish' (Danna, born and brought up in Scotland but living in Australia); 'I'm proud to be Scottish so yeah I tell people' (Gunna, living in London); 'I am happy to be Scottish and I am proud of it' (Tiree, splits time between Aberdeen and Edinburgh). Some participants thought it important to emphasise that, in identifying as Scottish, they were not rejecting a British identity. This suggests that Scottish pride can also be 
consonant with being inclusive and open-minded. It might also be argued that pride in the nation is a key component in 'becoming' Scottish (Bond and Rosie, 2006: 623).

On the other hand, participants still saw Scottish identity and culture as distinct from British; for example, Hirta reflected on growing up just outside of London versus visiting family in Scotland:

The whole pace of life is different I think. And Scottish people's attitudes to life in general - like everyone is so much more relaxed. I still think you get the driven attitude from everyone but it's at a much more caring and inclusive level if you know what I mean? You can walk down the street and just be a number, a random face in England and when you're here people stop and say 'hi'.

Scottish celebrations were also regarded by participants as a key symbol of Scotland. Scottish weddings, in particular, were referred to throughout the interviews:
Being at a Scottish wedding is so different from an English wedding. I think music is a big part of Scotland, like a ceilidh band. I think that is so typically Scottish and it gives you a sense of pride in your country when you hear that music, or when you're at a ceilidh with your friends or you hear bagpipes. I think that's probably the times when I feel most Scottish compared to any other time, or where I really notice it (Skye).

A key reason that some of the participants chose to reinforce the British side of their identity when asked the Moreno question (1988) seemed to stem from the Scottish Independence Referendum. The participants all mentioned this during interview, although this was completely unprompted. Most participants were keen not to be regarded as anti-British in any way, even those who revealed that they voted for Scottish independence. Participants were split in their views on Scottish independence, with around half the sample in favour and the other half against.

Those who were antipathetic towards Scottish independence were still very passionate 
about their Scottish identity and might, therefore, be considered 'cultural nationalists' (McCrone et al, 1995: 182). This supports other studies that found strong feelings of national identity and pride did not always correlate with nationalist political views and strong feelings towards an independent Scotland (McCrone et al, 1995; Bond and Rosie, 2002).

Overall there was a sense of belonging to Scotland, which most of the participants regarded as home and somewhere they felt comfortable and secure (Bond and Rosie, 2006; McCrone, 2017). Home and a sense of belonging were imagined differently at times and when reflecting on where they belonged participants tended to identify with a more localised city identity, e.g. Glasgow and Edinburgh (McCrone, 2017). However, this appeared to be less influential in the case of Aberdeen, where only one participant (Arran) referred to Aberdeen as somewhere she felt she belonged. Participants did not always regard the place in which they were living at the time of interview (e.g. London or Aberdeen) as the place to which they belonged ultimately. They associated belonging more strongly with a sense of feeling settled and where they would eventually end up. In this sense, participants appeared to agree that their Scottishness had grown and would remain salient throughout their lives. Indeed, the findings suggest that this might even increase further over time.

Connotations of home and belonging were particularly strong amongst the participants who were living outside of Scotland. They spoke of becoming more conscious of their Scottish identity and felt this was something that had become more important to them. This idea was evident in some of their imagery and is illustrated in Figures 6 and 7. Both posts make explicit references to Scottish style and identity in the caption but only one participant (living outside of Scotland) has visually styled herself in what could be regarded an overtly Scottish way. Both images are constructed around the participants' fashion identities and form part of pre-planned photoshoots. 


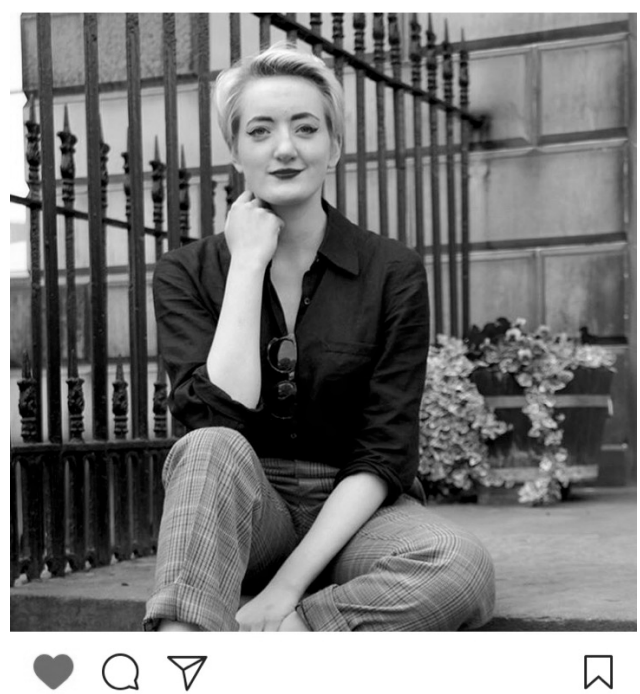

\#ontheblog tomorrow will be a brand new outrit snoot celebrating modern Scottish style, with photos by \#ootd \#lotd

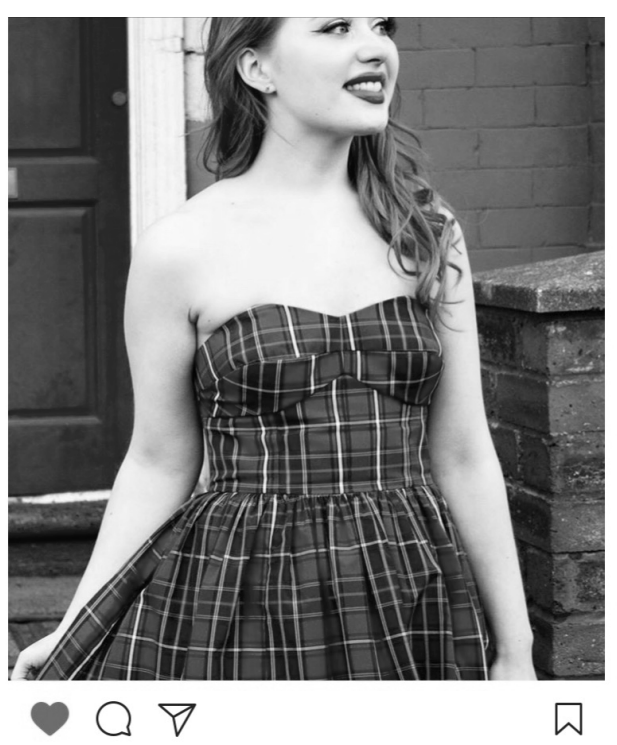

Happy St Andrew's Day to all my fellow Scots, at home or elsewhere! $\boldsymbol{\otimes}$ I've got a new post on the blog explaining why I'm proud of my Scottish heritage $\boldsymbol{X}$ photo by

Figure 6: Eday in Scotland

Iona (Figure 7), who was living in London at the time of interview, was the only participant who constructed her appearance in what might be regarded as a more stereotypically Scottish style; she explained that her unnaturally bright red hair was inspired by her Scottish heritage and felt this helped her to stand out in both offline and online settings.

Participants were asked to reflect on symbols of Scottish identity, building on the work of Crane et al (2004) who found these were significant. Crane et al's research took place in America and the authors found that clothing was most important to those individuals who were exploring their ancestral roots for the first time and wanted to convey their Scottish identity explicitly. They suggest that this might become less important as individuals begin to feel more complete in their Scottish identity. The current research findings (as illustrated in Figures 6 and 7) suggest that the adoption of a discernibly Scottish style might be more significant to those living outside of Scotland.

Most participants were quick to distinguish between what they saw as genuine and more stereotypical symbols of Scottishness. They tended to regard personality and place-related symbols as more authentic than material items, such as tartan. When discussing Scottish style more broadly and reflecting on their own style, participants did 
not mention tartan or traditional woven textiles in any great detail. Some acknowledged tartan as a symbol of Scottishness but felt it was not a strong part of their own personal style and perhaps then not representative of modern Scottish fashion. Gunna, who was living in London, felt that wearing tartan in the wrong context as a Scottish person could be damaging to her personal identity:

I remember when I first started an internship in London and I wore tartan trousers and it was the worst idea ever: like the classic Scottish person wearing tartan \{laughs\}. But I feel like it was just on trend at that time, it was just a coincidence. Nothing happened, I just felt like maybe I shouldn't be wearing this to work, because people are going to think I'm just wearing it because I love Scotland so much \{laughs\}. And actually, yeah, I do love it but it is in fashion right now as well so it's semi-acceptable \{laughs\}.

Arran, who was living in Aberdeen, revealed her decision to wear a tartan skirt on the day of the Scottish Independence Referendum vote; she identified herself as in favour of Scottish independence and admitted that her outfit choice was entirely influenced by her political view on this day. By wearing tartan Arran was communicating her proindependence stance:

The day of the Independence Referendum, I decided to put on a tartan skirt and walk about \{laughs\}.

These examples illustrate, from two very different viewpoints, that the choice to wear tartan as a Scottish person might be regarded as a form of discourse, synonymous with a heightened feeling of Scottish pride. Although two participants identified as 'Scottish girl[s] in London', Iona's explicit Scottish styling (Figure 7) contrasts with Gunna's experience of wearing tartan outside of Scotland. The examples suggest that this might be more appropriate online where an individual might wish to stand out and be remembered.

Although tartan was not regarded as an authentic symbol of contemporary Scottish style, it was recognised as a key component of cyclical fashion trends. Participants did 
not reject the idea of tartanry and those who mentioned tartan recognised it was part of Scotland's fashion story (Brown, 2010). However, they did not see it as sufficient and inclusive of a more diverse Scotland and its people.

The following discussion explores those ideas that participants felt were more authentic and genuine symbols of Scottish identity and style. These can be loosely separated into those concerning Scottish people and Scotland as a place.

\section{People as a symbol of Scottish identity}

Throughout the interviews participants were sentimental in their view of Scotland and the people who live there. They regarded Scotland in an exceptionally positive manner and felt that a Scottish identity was distinctive and attractive in offline and online settings. Indeed this was a key motivation for conveying their Scottish identity online.

Realistically, I don't think you'd get ... a bigger sense of identity and a national community as you do in Scotland (Hirta).

Scottish people were highlighted as symbolic of Scottish identity and regarded broadly as 'warm and welcoming', where it was also felt that they were likely to be perceived in this way by others. This was expressed differently by the variety of participants but seemed to amount to the fact that Scottish people were seen as friendly, inclusive and affectionately received by other nations. In conveying this idea, participants reflected on offline experiences, such as meeting new people or being received positively when travelling outside of Scotland. Generally, these were times when they had been recognised for their accent (Kiely et al, 2001) and Scottishness was described as a conversation starter:

I spent time in the summer interning in New York a couple of years ago and I felt very proud of being Scottish. I suppose partly because it was my identifying factor, something that made me different. People were really interested in me, they wanted to know about me, they loved my accent, they loved the way I look, 
they wanted to know about my culture. And it was a bit of a shock coming back to Scotland and no one batting an eyelid at me and that was very strange (Iona).

Participants felt that they were able to project the warmth they associated with Scottish people online by taking the time to engage with their followers, e.g. responding to messages. They also felt able to portray this through the production of relatable content, e.g. presenting themselves in familiar settings and wearing attainable fashion garments, where most participants opted for Scottish brands, budget high-street retailers and charity shops over luxury high-end styles. Participants also referred to sarcasm and a self-deprecating sense of humour, which they felt was common amongst Scottish people and enabled them to appear modest, down-to-earth and likeable. These features were positioned in contrast with London fashion influencers whom participants felt presented more aspirational and less achievable lifestyles.

The participants in this study were conscious that their audience was made up of Scottish and non-Scottish people and that both might appreciate their content but in different ways, e.g. the familiarity of places and access to new experiences. Some chose to use recognisable Scottish phrases and, in doing so, conveyed a Scottish voice in their posts (Douglas, 2006). This was always limited to those phrases that might be widely recognised amongst a potentially global audience as being Scottish, e.g. 'wee' and 'bonny'.

In discussing their personal style and reflecting on how this might be influenced by their Scottish identity, participants had difficulty in doing so. They struggled with the idea that it might be possible to 'look Scottish' but felt that their style was influenced by their national identity in subtler ways. Some participants spoke of bold style choices that they felt stemmed from a sense of their self as Scottish; for example, where they felt confident in experimenting with styles that might be considered more daring or that might challenge more mainstream fashion trends, like tattoos, bright colours and unconventional materials. One participant described Scottish style as 'more about mix and match, find your own style' than in London where 'it's more about flashing the cash and designer labels'. 
I feel like a lot of Scottish people are quite brave in their appearance ... Although we can be quite insecure, I think a lot of people express themselves easily, or they're quite proud, they're quite brash in their appearance - like brightly coloured hair or they're not really that scared (Tiree).

This appeared to also stem from a sense of Scottish 'attitude', where participants felt that Scottish people by nature did not follow the crowd when expressing themselves, in terms of both their opinions and fashion choices. This was described by one participant as an attitude of 'defiance' and a dislike of being told what to do that she felt was a trait amongst Scottish people. Participants spoke about their love of independent brands, designers (Figure 8) and supporting local businesses, such as coffee shops and restaurants (Figure 9).

I think there's a [big] independent scene in Scotland. Erm, particularly in Glasgow. But also Edinburgh and Aberdeen as well ... It's more about find[ing] your own style. I suppose smaller, independent businesses. I suppose we kind of make our own fashion. I find it's very mix and match and kind of eclectic. Like it's not just following everything that's in vogue or buying something because someone told me to. It's like you buy it because you want to ... it's kind of like a defiance ... (Cara). 


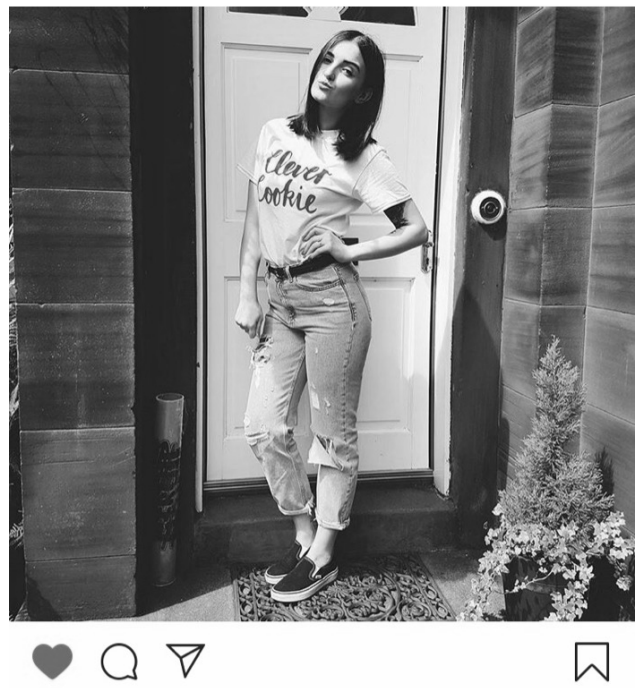

lam obsessed with my clever cookie tfeeling like a clever wee cookie 0

Figure 8: Independent fashion choices

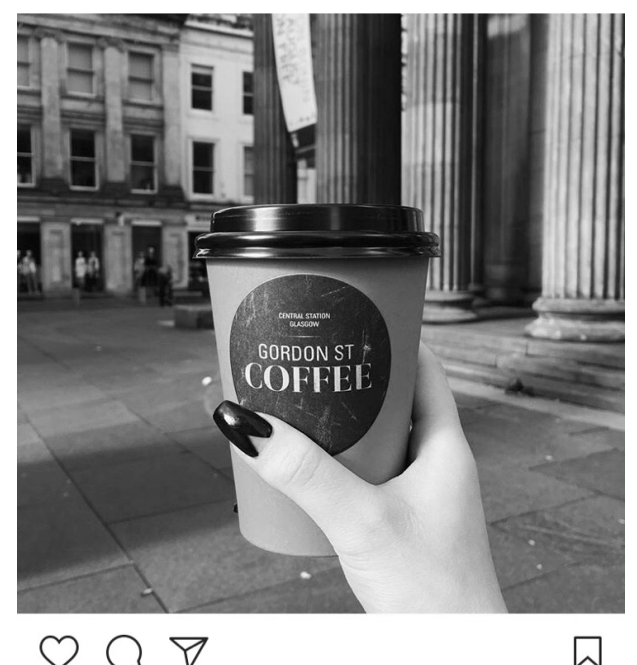

Good morning Glasgow // \#coffee

View all 29 comments 4 AUGUST 2016

Figure 9: Independent lifestyle choices

Participants also spoke of signature poses and image aesthetics that they felt were immediately recognisable as theirs. This sense of individuality amongst participants was expressed differently throughout the sample and arguably it further reinforces the ethos of originality that is common amongst Scottish style influencers.

\section{Place as a symbol of Scottish identity}

The influencers who took part in this study expressed an interest in sharing photos that they had taken in unique or intriguing settings. These settings, at first glance, might appear as simply the backdrop to an outfit post, but these were often quite significant to the participant being studied. At times these settings were discovered and shared in an impulsive manner, usually when they were new to the participant. More often, they were more carefully constructed, where the participant had set out to intentionally use a setting as part of a photoshoot. In these cases, the background of the photo might reveal about the participant's identity than the foreground of the image (Figure 10). The fact that attention was not always drawn to these backgrounds in an explicit way, in the accompanying caption, suggests that these might be viewed as a natural and authentic vision of Scotland (Figure 11). 


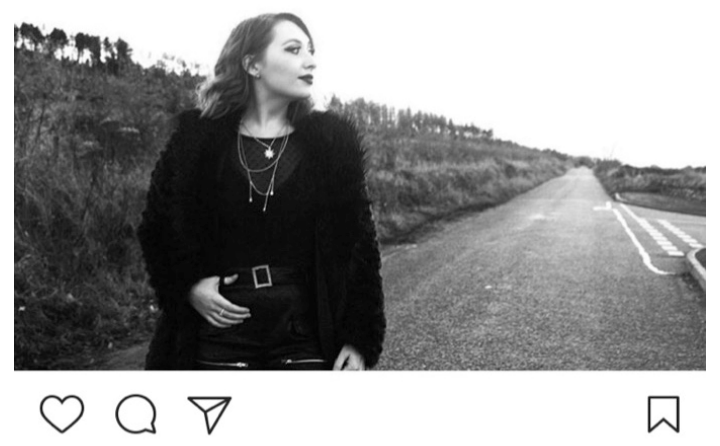

Macke the most of the beautiful backdrop of home and shot this dark and brooding look for the blog \#autumn \#winter \#woodlands \#ootd \#wiwtd \#fblogger \#scottishblogger \#scotland \#Elgin \#fauxfur \#gothic \#indie \#ginger \#redhead \#leather \#nature

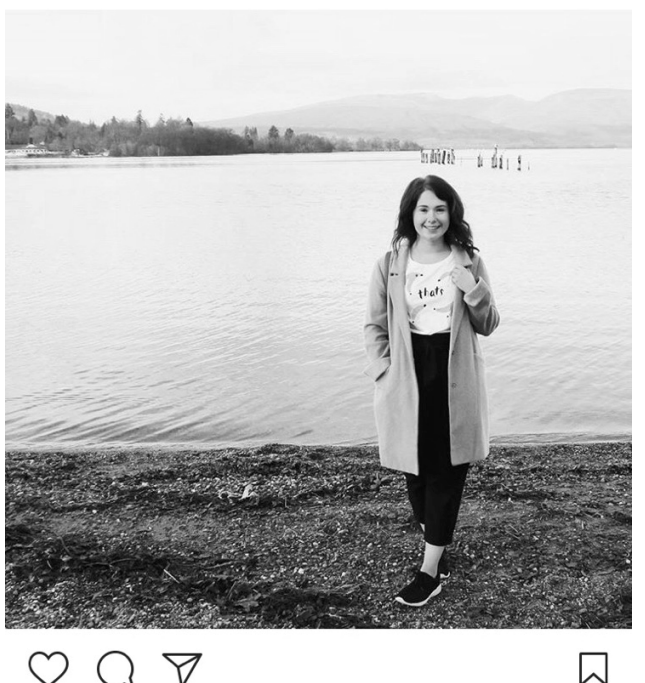

Winter walks

View all 7 comments

27 DECEMBER 2016

Figures 10 and 11: Scottish setting as a backdrop

Participants spoke of Instagram as a 'positive place' and were keen to inspire their followers by promoting a positive lifestyle. One way in which they conveyed this positivity was through the use of outdoor imagery; this was a preference amongst all participants and a key component of how they expressed themselves online.

A number of the sample posts included features such as cobbles, old buildings and stone walls. Many also contained elements of nature, whether simply greenery or more dramatic settings such as lochs and walled gardens. In their use of setting in this way, it is argued that Scottish fashion influencers are redefining the traditional definition of street style, where fashion is usually depicted against a less remarkable urban setting (Rocamora and O'Neill, 2008). Participants in this study were all city dwellers and so their preference for rural and historic backdrops for outfit posts is perhaps one of the most visible ways in which they were able to use their Scottish identity as a means to stand out online (Figure 12). 

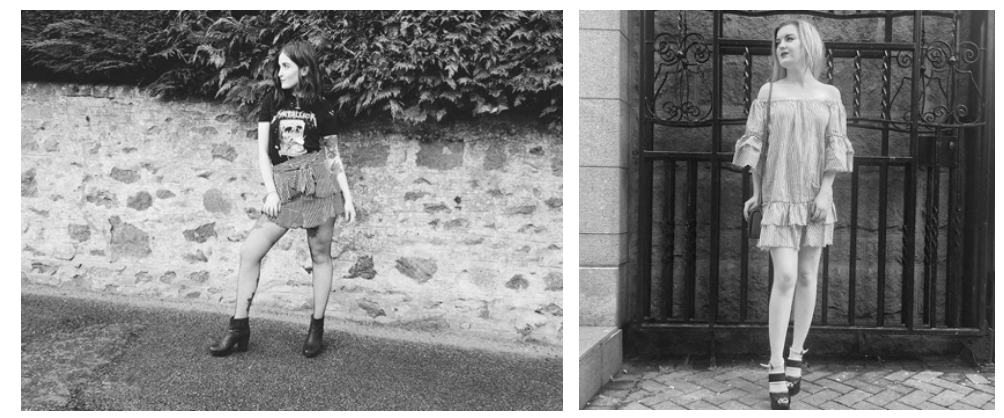

Figure 12: Illustrations of Scottish street style

It is a theme in the literature that individuals are apt to look to the past when trying to make sense of their identity (McCrone et al, 1995; Kjartansdóttir, 2011). Scotland is regarded as a country with a rich history and heritage (Pittock, 1991; Houston, 2002; Shields, 2010). It has been argued that 'national memory' is particularly important in stateless nations, such as Scotland (Edensor, 1997: 175) where one might wonder 'is it only imagining Scotland that keeps it alive?' (McCrone et al, 1995: 196; Anderson, 1983). A sense of Scottish past and history was significant in helping participants feel connected to Scotland (McCrone et al, 1995; Kjartansdóttir, 2011). This idea was expressed most strongly in relation to heritage tourism as a lifestyle element on Instagram but also in some of the anecdotes that participants shared:

I'd say a time when I felt maybe more Scottish was actually recently when I was in Aberdeen and working in Boots. An elderly gentleman came in a few times and he would always stop and chat to me. And at one point the conversation got on to the fact that he has family in the Highlands, that have the same last name as my mum - like a clan, the Taylor clan. And then he was really excited about it and spoke to me, and that made me happy. And then the next week he came in and brought in this lambs' wool scarffrom the clan to show me and then he actually gave it to me to take home. It was just a random man that I didn't know and he was just so happy about it and that's what I like about Scotland, that made me feel proud to be Scottish (Tiree).

McCrone (2017: 1) distinguishes between Scottish history and 'the past', where the latter connotes a more romantic memory of historical fact. A sense of Scottish past and heritage seemed to be particularly important to some of the participants in this study, 
who felt 'history' was an important signifier of Scotland. Throughout the interviews, participants reflected on time spent visiting historic attractions in Scotland (Figure 13).

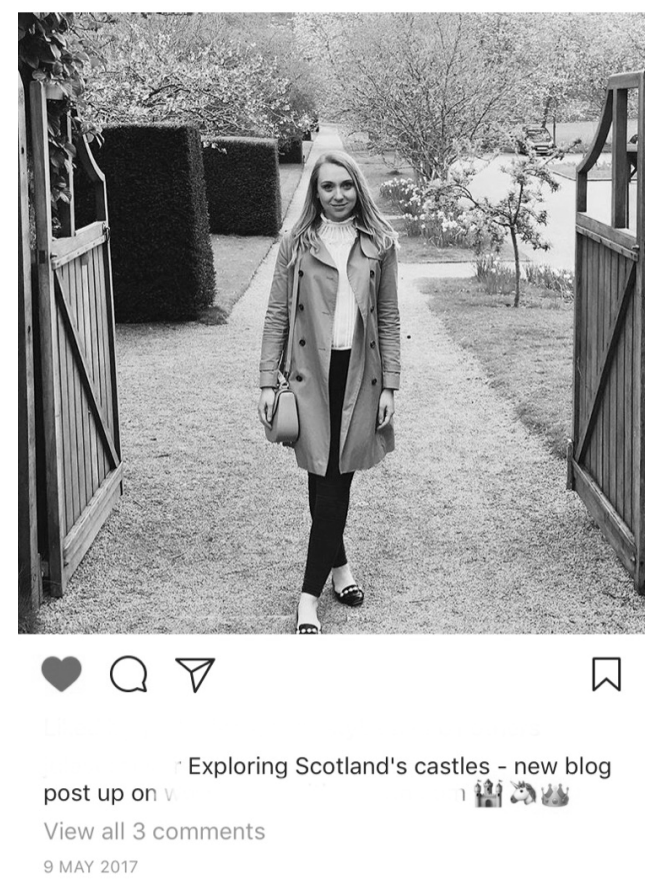

Figure 13: Barra at Fyvie Castle

This supports the findings of McCrone et al (1995) who observe an increase in heritage tourism from the late $20^{\text {th }}$ century. However, none of the participants seemed to regard historic destinations as constructions or products of a Scottish heritage industry as McCrone et al (1995) suggest. Those who spoke about visiting these attractions regarded them as genuine signifiers of Scotland and its history. These outings were considered time well spent, as meaningful and fulfilling experiences. Some participants appeared to be particularly enthusiastic about sharing these trips on Instagram:

I don't know if people really pay attention to what is around us. A lot of people are like 'what are we going to do today? Let's go to the cinema or to Union Square!' But in this area you just have to leave the city for like 5 minutes and you've got, you know, Dunnottar, Crathes, Drum ... (Barra)

This suggests that unique place-related outings (like visiting heritage sites) might be considered more valuable than more placeless activities, such as visiting 
shopping malls and cinemas. In styling their online selves in this way, it might be argued that participants were using their Scottish identity and place online as a form of cultural capital (Bourdieu, 1986; McCrone et al, 1995). Sometimes these attractions were used as a backdrop, upon which the influencer presented themselves but often they were also presented as people-less landscapes that had been photographed by the participants, where their followers were able to see Scotland through their eyes (Figure 14).
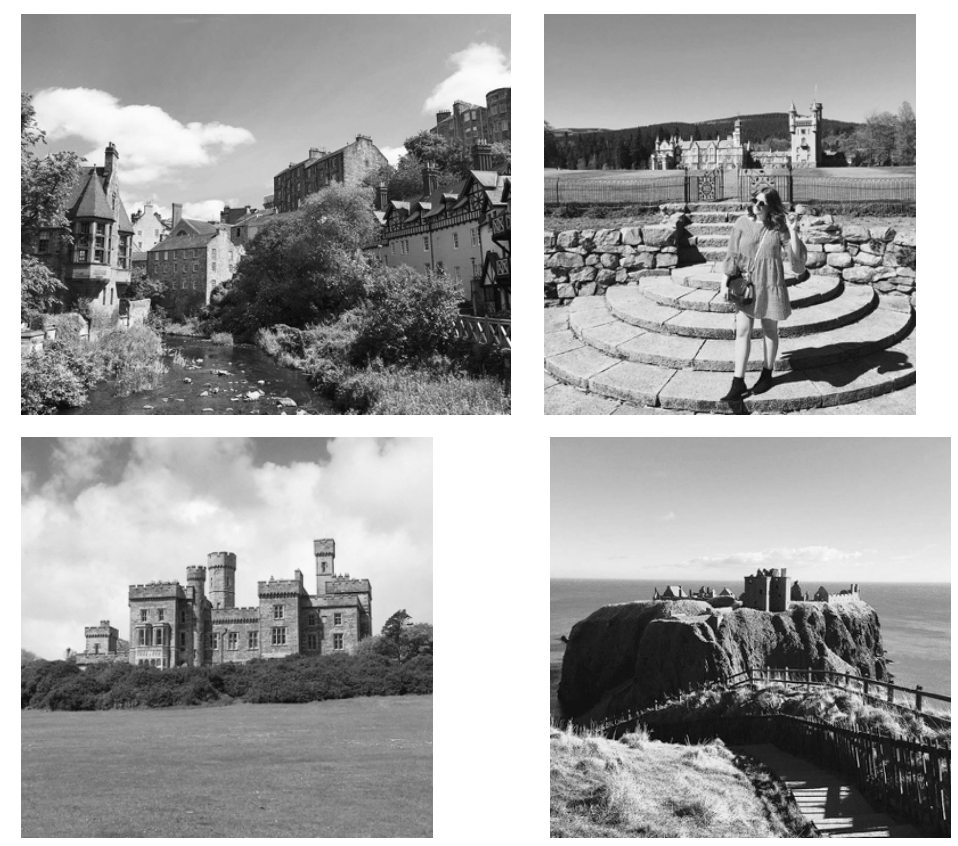

Figure 14: Outdoor illustrations of Scotland

In this manner, participants might be regarded as national explorers who are styling perceptions of Scotland as a place. Much of the imagery they provided was themed around this idea where they were keen to present Scotland as an attractive tourist destination or place to live (Figure 15). 

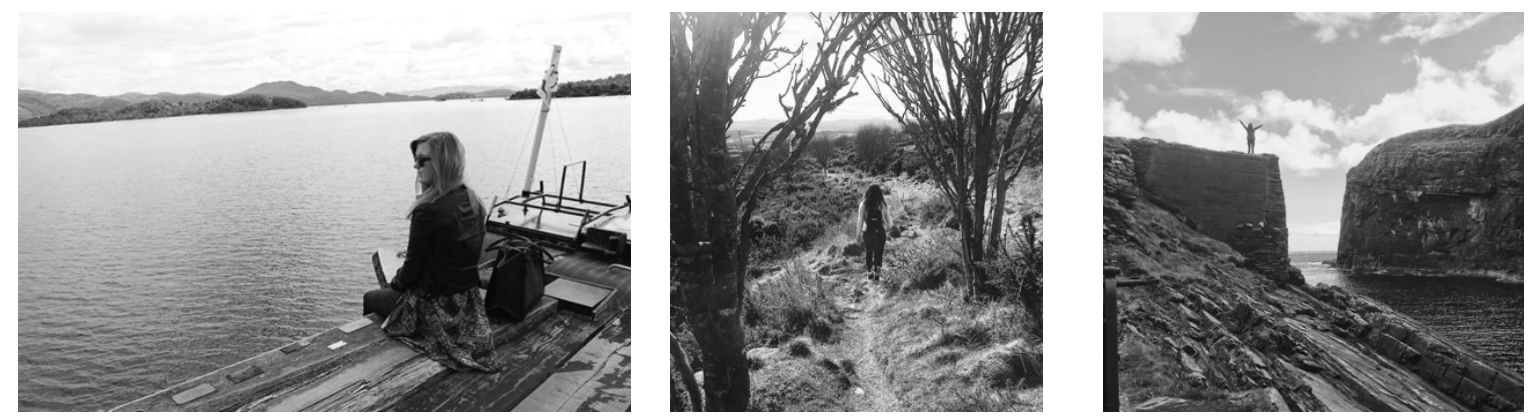

Figure 15: Exploring Scotland

One participant spoke of attempting to 'find the beauty in places' and, in particular, her hometown of Aberdeen. She relayed compliments she had received from her online audience, e.g. one follower had told her 'I've never seen Aberdeen in the way you see Aberdeen'. Audience feedback of this sort was important to the participants in this study and often appeared to shape the way they presented themselves online.

The earlier idea of Scottish people as warm is intriguing in its contrast with the Scottish climate, which was acknowledged to be cold. Participants seemed to feel able to convey their warmth successfully through Instagram by appearing friendly and responsive towards their followers, as well as through the production of a relatable lifestyle. However, they also reflected on the harsher reality of the Scottish weather and its influence on their style choices. All the participants expressed a preference for autumnwinter styles and referred to boots, coats and scarves as a key part of this aesthetic. Not only did they feel a need to dress in this way for functional purposes but they also expressed a natural inclination towards these styles. In all cases this seemed to stem from a sense of comfort, familiarity and belonging to Scotland, where even those who were born in Scotland (living in London and Australia) expressed an enduring preference for autumn-winter fashion:

I prefer winter to summer because I prefer dressing in winter... maybe that's because I'm used to it. But when it comes to London, as much as it's nice, it's sunny, I'm like 'oh my god what am I supposed to wear? A dress and, like, no jacket? This is weird!' Whereas when you go to Scotland, it's all about layering. I prefer that definitely (Gunna). 
It is intriguing that even London was considered as somewhere that it was possible to embrace summer styles in a way in which it was not in Scotland. Throughout the interviews, participants drew comparisons between Scotland and London. They all had experiences of visiting and/ or living in London and saw Scotland as an escape; a place where the air is fresher, the pace of life is slower and the grass is perhaps quite literally greener. However, London as the epicentre for UK fashion was also regarded as a place that had more to offer in terms of commercial opportunities. These ideas suggest that the Highland myth surrounding Scotland as a place is still strong in the contemporary representations of the nation.

\section{Conclusions}

This study has explored the construction of Scottish identity and place amongst female fashion influencers on Instagram. Previous studies of Scottish fashion, as well as the information and illustrations surrounding Scottish fashion are lacking and focused primarily on Scottish textiles, upholding the image of tartanry. This study helps pave the way for further research in the field of Scottish fashion and style.

Through qualitative interviews and analysis of participants' imagery new themes and ideas around contemporary Scottish identity and style were uncovered. Fashion and style influencers are recognised as increasingly significant in the fashion industry today and so it is argued that, in identifying as Scottish or placing themselves within Scotland, these women are shaping contemporary representations of Scotland in what is a potentially global arena, acting as modern-day cultural icons.

Participants were proud to be Scottish and this was one of their key motivations for constructing Scottish identity online. They regarded Scottish identity as a positive feature and something that would make them stand out and appear attractive online. Participants rejected what they thought of as stereotypes of Scotland and tartan fell into this category; they recognised its value for the fashion industry at large but felt it was not representative of authentic Scottish style today. New symbols of Scottish style were uncovered including brave, bold and original fashion choices and autumn-winter styles. 
However, elements of the Scottish myth were upheld in the styling of these images, where participants favoured historic and people-less settings as a backdrop for outfit posts. Future research might seek to explore these ideas further, perhaps in the more localised context of Scotland's cities. Research into audience reception of influencer output would also be valuable.

\section{References}

Alexander, E. (2012). Chanel hosts an 'exceptional' Scottish spectacular. Vogue. [Online]. Available at: http://www.vogue.co.uk/article/chanel-scotland-show-atlinlithgow-palace-vogue-verdict. [Accessed on: $26^{\text {th }}$ March 2017].

Anderson, B. (1983). Imagined communities. London: Verso.

BBC, (2012). Chanel to stage fashion show at Linlithgow Palace. [Online]. Available at: https://www.bbc.co.uk/news/uk-scotland-scotland-business-20319727.

[Accessed on: 24th April 2018].

Bechhofer, F. and McCrone, D. (2009). National identity, nationalism and constitutional change. London: Palgrave MacMillan.

Blanks, T. (2012). Chanel pre-fall 2013. Vogue. [Online]. Available at: https://www.vogue.com/fashion-shows/pre-fall-2013/chanel. [Accessed on: 24th April 2018].

Bond, R. and Rosie, M. (2002). National identities in post-devolution Scotland. Scottish Affairs, 40(1), pp. 34-53.

Bourdieu, P. (1986). The forms of capital. In Richardson, J. E. Handbook of theory of research for the sociology of education. Westport, CT: Greenwood Press.

Bond, R. and Rosie, M. (2006). Becoming and belonging: national identity and exclusion. Sociology, 40(4), pp. 609-626.

Browne, K. (2007). Snowball sampling: using social networks to research nonheterosexual women. Qualitative Research in Psychology, 11(1), pp. 47-60.

Butt, J. (1987). Scottish textile history. Edinburgh: Merkat Press.

Cederlund, C.O. (2011). The modern myth of the Viking. Journal of Maritime Archaeology, 6(1), pp. 5-35. 
Cheape, H. and Anita Q. (2005). Historical and analytical research of dyes in early Scottish tartans. Scientific analysis of ancient and historic textiles: informing preservation, display and interpretation: postprints, first annual conference, 1315th July 2004. London: Archetype Publications.

Crane, T. C., Hamilton, J. A. and Wilson, L. E. (2004). Scottish dress, ethnicity and selfidentity. Journal of Fashion Marketing and Management, 8(1), pp. 66-83.

Crawford, R. (2007). Scottish books. London: Penguin Books.

Crawford, R. (2014). Bannockburns: Scottish independence and literary imagination. Edinburgh: Edinburgh University Press.

Douglas, F. (2006). Scottish newspapers, language and identity. Edinburgh: Edinburgh University.

Edensor, T., 1997. National identity and the politics of memory: remembering Bruce and Wallace in symbolic space. Environment and Planning D: Society and Space, 15(2), pp. 175-194.

Edwards, J. (2014). Vivienne Westwood uses catwalk show to say 'yes' to Scottish independence. Cosmopolitan. [Online]. Available at: https://www.cosmopolitan.com/uk/fashion/style/news/a29662/viviennewestwood-catwalk-show-say-yes-scottish-independence-political/. [Accessed on: $14^{\text {th }}$ February 2019].

Faiers, J. (2008). Tartan. Oxford: Berg Publishers.

Fulton, A. (1991). Scotland and her tartans. London: Hodder and Stoughton.

Grierson, S., Duff, D. G. and Sinclair, R. S. (1985). The colour and fastness of natural dyes of the Scottish Highlands. Coloration Technology, 101(7-8), pp. 220-228.

Houston, R. A. (2002). Scottish literature and the Scottish identity: illiteracy and society in Scotland and Northern England 1600-1800. Cambridge: Cambridge University Press.

Jones, N. (2014). British Fashion Council pushes for 'no' vote on Scotland. WWD, 208(58), pp. 2.

Kiely, R., Bechhofer, F., Stewart, R. et al, (2001). The markers and rules of Scottish national identity. The Sociological Review, 49(1), pp. 33-55.

Kjartansdóttir, K. (2011). The new Viking wave: culture, heritage and capitalism. In Chartier D. Iceland and Images of the North. Pp. 461-480. Quebec, Canada: Quebec University Press. 
Larkin, M. and Thompson, A. (2012). Interpretative phenomenological analysis. In Thompson, A. and Harper, D. Qualitative research methods in mental health and psychotherapy: a guide for students and practitioners, pp. 99-116. Oxford: John Wiley \& Sons.

Lennon, H. (2016). How big is Scotland's fashion and textile industry? The Scotsman. [Online]. Available at:

http://www.scotsman.com/lifestyle/culture/fashion/how-big-is-scotland-sfashion-and-textile-industry-1-4043515. [Accessed on: 25 th July 2017].

Lindfield-Ott, K. (2018). 'How they turned the whole world tartan': Scottishness, Britishness and the Bay City Rollers. British Identities. [Online]. Available at: https://britishidentities.wordpress.com/2015/09/21/how-they-turned-thewhole-world-tartan-scottishness-britishness-and-the-bay-city-rollers/. [Accessed on: 23 ${ }^{\text {rd }}$ February 2018].

Marcella, M. and Rowley, S. (2015). An exploration of the extent to which project management tools and techniques can be applied across creative industries through a study of their application in the fashion industry in the North East of Scotland. International Journal of Project Management, 33(4), pp. 725-746.

Martin, M. (2009). The mighty Scot. Nation, gender and the nineteenth century mystique of Scottish masculinity. New York: State University of New York Press.

McCrone, D., Morris, A. and Kiely, R. (1995). Scotland the brand. Edinburgh: Edinburgh University Press.

McCrone, D. (2017). The new sociology of Scotland. London: SAGE Publications Ltd. McKeen, C. (2009). Dundee Renaissance to Enlightenment. Dundee: Dundee University Press.

Mora, E. and Rocamora, A. (2015). Letter from the editors: analyzing fashion blogs: further avenues for research. Fashion Theory: the Journal of Dress, Body and Culture, 19(2), pp. 149-156.

Moreno, L. (1988). Scotland and Catalonia: the path to home rule. Scottish Government Yearbook 1988. Available at: http://www.scottishgovernmentyearbooks.ed.ac.uk/record/23014/1/1988 11 ScotlandandCatalonia.pdf. [Accessed: 17 th January 2017]. 
Mower, S. (2016). Spring 2017 ready-to-wear Alexander McQueen. Vogue. [Online]. Available at: https://www.vogue.com/fashion-shows/spring-2017-ready-towear/alexander-mcqueen. [Accessed on: $26^{\text {th }}$ March 2017].

Percival, J. M. (2010). Rock, pop and tartan. In Brown, I. From tartan to tartanry: Scottish culture, history and myth. Pp. 13-31. Edinburgh: Edinburgh University Press Ltd.

Pittock, M. G. H. (1991). The invention of Scotland: the Stuart myth and the Scottish identity 1638 to the present. New York: Routledge.

Platman, L. (2011). Harris Tweed: from land to street. London: Frances Lincoln Limited.

Porac, J. F., Thomas, H. and Baden-Fuller, C. (1989). Competitive groups as cognitive communities: the case of Scottish knitwear manufacturers. Journal of Management Studies, 26(4), pp. 397-416.

Pringle of Scotland, (2009). [Film]. Directed by Ryan McGinley. Available at: https://www.youtube.com/watch?v=m7FLDXTGIy0. [Accessed on: 10 th January 2016].

Rae, J. (2016). Warm covers: a Scottish textile story. Bristol: Sansom and Company.

Reed, A. (2005). 'My blog is me': Texts and persons in UK online journal culture. Journal of Anthropology, 70(2), pp. 220-242.

Rocamora, A. and O'Neill, A. (2008). Fashioning the street: images of the street in the fashion media. In Shinkle, E. Fashion as photograph, pp. 185-199. London: I.B. Taurus \& Co.

Rocamora, A. (2011). Hypertextuality and remediation in the fashion media. Journalism Practice, 6(1), pp. 92-106.

Serge Reinach, S. (2015). National identities and international recognition. Fashion Theory: the Journal of Dress, Body and Culture, 15(2), pp. 267-272.

Shields, J. (2010). Sentimental literature and Anglo-Scottish identity, 1745-1820. Cambridge: Cambridge University Press.

Skov, L. (2010). Dreams of small nations in a polycentric fashion world. Fashion Theory: the Journal of Dress, Body and Culture, 15(2), pp. 137-156.

Young, C. and Martin, A. (2017). Tartan and tweed. London: Frances Lincoln Limited. 